\title{
All-optical wavelength conversion of short pulses and NRZ signals based on a nonlinear optical loop mirror
}

Yu, Jianjun; Zheng, Xueyan; Peucheret, Christophe; Clausen, Anders; Poulsen, Henrik Nørskov; Jeppesen, Palle

Published in:

Journal of Lightwave Technology

Link to article, DOI:

$10.1109 / 50.850747$

Publication date:

2000

Document Version

Publisher's PDF, also known as Version of record

Link back to DTU Orbit

Citation (APA):

Yu, J., Zheng, X., Peucheret, C., Clausen, A., Poulsen, H. N., \& Jeppesen, P. (2000). All-optical wavelength conversion of short pulses and NRZ signals based on a nonlinear optical loop mirror. Journal of Lightwave Technology, 18(7), 1007-1017. https://doi.org/10.1109/50.850747

\section{General rights}

Copyright and moral rights for the publications made accessible in the public portal are retained by the authors and/or other copyright owners and it is a condition of accessing publications that users recognise and abide by the legal requirements associated with these rights.

- Users may download and print one copy of any publication from the public portal for the purpose of private study or research.

- You may not further distribute the material or use it for any profit-making activity or commercial gain

- You may freely distribute the URL identifying the publication in the public portal 


\title{
All-Optical Wavelength Conversion of Short Pulses and NRZ Signals Based on a Nonlinear Optical Loop Mirror
}

\author{
Jianjun Yu, Xueyan Zheng, Christophe Peucheret, Anders T. Clausen, Henrik N. Poulsen, and \\ Palle Jeppesen, Member, IEEE
}

\begin{abstract}
Wavelength conversion of short pulses at $10 \mathrm{GHz}$ based on a nonlinear optical loop mirror (NOLM) is experimentally and numerically investigated for the case of small group velocity dispersion and walkoff between the control pulses and continuous lightwaves. Experimental and numerical simulation results show that the pulsewidths of the converted signals at different wavelengths are almost the same, and the pulsewidths are compressed when the peak power of the control pulse is smaller than a certain value. An RZ optical source containing eight wavelengths having a high sidemode suppression ratio, equal amplitudes and almost the same pulsewidths is obtained by using wavelength conversion in a NOLM consisting of a common dispersion shifted fiber. $10 \mathrm{~Gb} / \mathrm{s} \mathrm{NRZ}$ wavelength conversion based on the NOLM is demonstrated for the first time and certain conclusions in some of the references are confirmed by our experimental results.
\end{abstract}

Index Terms-Cross-phase modulation (XPM), nonlinear optical loop mirror, optical time domain multiplexing (OTDM), wavelength conversion, wavelength-division multiplexing (WDM).

\section{INTRODUCTION}

W AVELENGTH conversion has been suggested as a method of enhancing routing options and network properties like reconfigurability, nonblocking capability and wavelength reuse [1], [2]. To achieve all-optical wavelength conversion, various strategies have been investigated. There are mainly two kinds of media: one medium is based on semiconductor optical amplifiers (SOA's), and methods are cross-gain modulation (XGM) [3], [4], cross-phase modulation (XPM) [5], [6], and four-wave mixing (FWM) [7]-[9]; the other medium is based on fibers, and methods are FWM [10] and XPM [11]-[13] in dispersion shifted fibers (DSF's). FWM is transparent to both modulation format and signal bit-rate [7]-[10]. The use of FWM in optical networks is possible only if high conversion efficiency and high signal-to-noise ratio (SNR) can be achieved, the latter being one of the main constraints of four-wave mixing (FWM) in semiconductor optical amplifiers (SOA's) due to the high amplified spontaneous emission (ASE) [7]-[9]. Because of the SNR degradation, regeneration cannot be realized by using FWM in SOA's. However, [14], [15] have shown the regenerative capability of wavelength conversion

Manuscript received September 28, 1999; revised February 8, 2000. The authors are with the Research Center COM, Technical University of Denmark, Building 349, Lyngby DK-2800, Denmark (e-mail: jy@ com.dtu.dk). Publisher Item Identifier S 0733-8724(00)05769-8. using an NOLM. SOA's are small and can be monolithically integrated with waveguides to form compact and polarization insensitive functional structures. But, owing to the relatively slow carrier recovery time of SOA's ( $\sim 1 \mathrm{~ns})$, nonreturn-to-zero (NRZ)-like output signals are obtained when the wavelength conversion is performed in SOA's by XGM or XPM, and this is not suitable for return-to-zero (RZ)-based networks [5]. However, nonlinear optical loop mirror (NOLM) based on silica fiber has the potential of attaining terabits per second switching operation due to the ultrafast optical nonlinearity; our experiments will demonstrate that the pulsewidths can be maintained, and even compressed when the walkoff defined in [11] between the CW waves and the control pulses is small. So, wavelength conversion based on a NOLM will be suitable for RZ based networks.

To implement practical NOLM wavelength conversion, polarization independent operation is indispensable [16]-[18]. A very simple method to overcome the polarization sensitivity of the NOLM has been experimentally demonstrated by twisting the fiber to generate circular birefringence [18]. Furthermore, experiments have demonstrated that the interference in a NOLM of a few kilometers of length is insensitive to environmentally induced changes in the linear refractive index of the fiber [16]-[19].

FWM, XPM, and XGM in SOA's have been demonstrated for NRZ wavelength conversion. But up to now, no NRZ wavelength conversion using a NOLM has been reported. In this paper, considering the effect of walkoff time between control pulses and continuous-wave (CW) light, wavelength conversion of short pulses at $10 \mathrm{GHz}$ based on a NOLM will be investigated by using numerical and experimental methods.

Broadband low-noise optical sources are of vital importance for future large-capacity flexible optical network utilization of both optical time-division multiplexing (OTDM) and wavelength-division multiplexing (WDM) [20]-[22]. It is an effective method to generate short pulses by using supercontinuum, but a dispersion-flattened fiber and a special WDM filter for filtering the channels will be needed to optimize the performance [20]-[22]. We will demonstrate that an RZ WDM optical source containing eight wavelengths having the same amplitudes and nearly equal pulsewidths is successfully obtained by using wavelength conversion in a NOLM consisting of a common DSF. Furthermore, the pulsewidth of the converted pulses can be maintained and even compressed after wavelength conversion. 


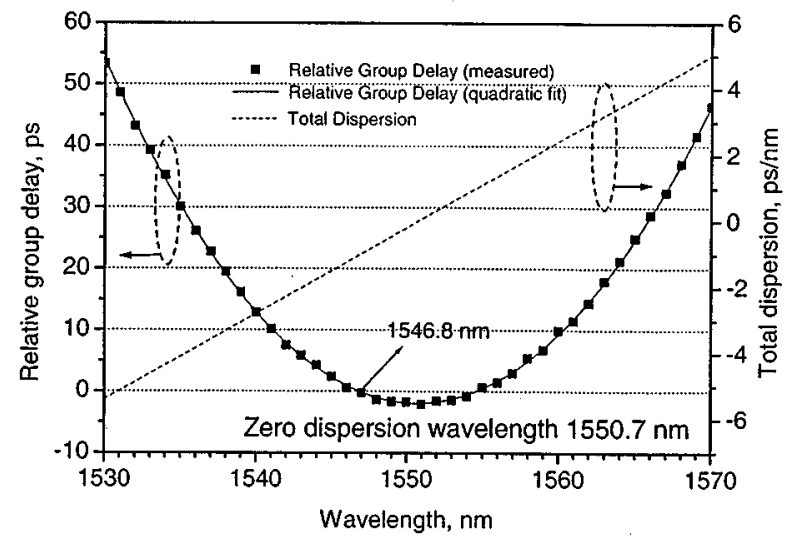

Fig. 1. Relative total group delay and total dispersion as a function of signal wavelengths for the DSF.

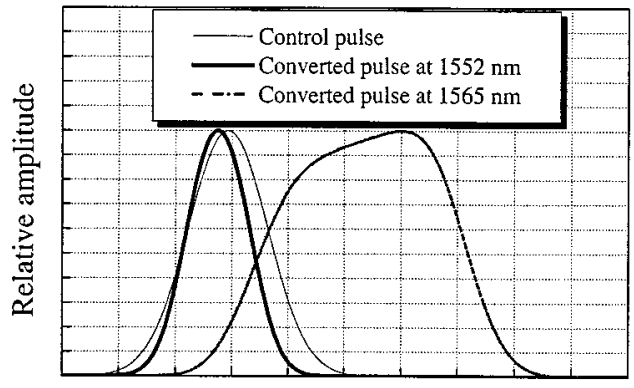

Time (5 ps/div)

Fig. 2. Numerical simulation waveforms of converted pulses at 1552 and 1565 $\mathrm{nm}$.

NRZ signals are often used because of their small bandwidth, however, up to now, no experiment of NRZ wavelength conversion based on an NOLM has been reported. We will demonstrate that also NRZ wavelength conversion based on an NOLM can be realized meaning that wavelength conversion in a NOLM is transparent to RZ and NRZ format. The conclusion in [11] that the nonlinear phase of the counterpropagating waves can be easily compensated just by adjusting the state of the polarization controller in the NOLM, and high ER of the converted signal can be obtained is confirmed by our experimental results.

This paper is divided into four sections. Section II includes some numerical simulations and experiments concerning wavelength conversion based on a NOLM for short pulses. An eight-wavelength RZ optical source having equal amplitudes and nearly the same pulsewidths is obtained by using wavelength conversion in a NOLM consisting of a common DSF. In Section III, 10-Gb/s NRZ wavelength conversion based on the NOLM is demonstrated for the first time and certain analytical results in the references are confirmed. In Section IV conclusions are given.

\section{WAVELENGTH CONVERSION OF SHORT PULSES}

A silica fiber based NOLM has the potential of attaining Tbit/s switching operation due to the ultrafast optical nonlin-

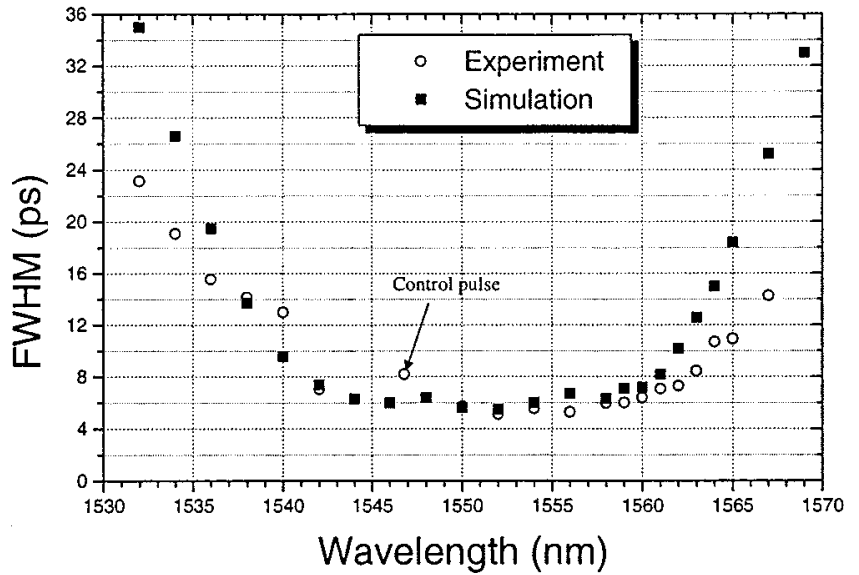

Fig. 3. FWHM pulsewidth for experiment and numerical simulation as a function of $\mathrm{CW}$ wavelengths. The peak power of control pulse is $150 \mathrm{~mW}$, and $\mathrm{CW}$ power is $4 \mathrm{~mW}$.

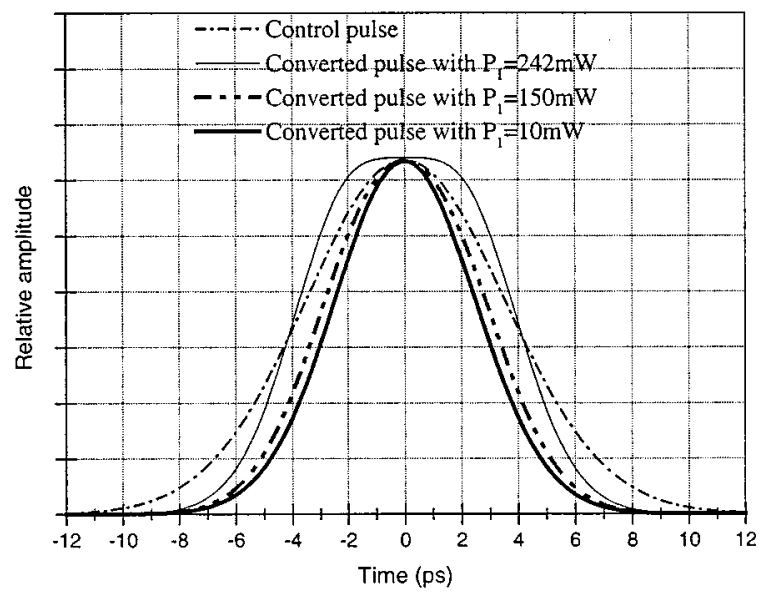

Fig. 4. Calculated pulse shapes with only XPM effect considered.

earity [23], [24], so the pulsewidth of converted pulses can be maintained. However, the walkoff between the control pulses and CW lightwave will broaden the pulsewidths of the converted signals [25]. The pulse-broadening effect can be eliminated by using dispersion flattened DSF's in NOLM's, however it is not easy to manufacture such fibers. Our experiment shows that the change in the converted pulsewidths with different converted wavelengths is very small. Furthermore, the pulsewidths of the converted signals are narrower than that of the control pulsewidth when the peak power of the control pulses, the wavelength of the control pulses and the CW lightwaves are chosen properly. The wavelength conversion based on the NOLM will be investigated using numerical and experimental methods, and the results of the numerical simulations and experiments are in good agreement. An RZ optical source containing eight wavelengths having the same amplitudes and nearly equal pulsewidths is successfully obtained by using wavelength conversion in a NOLM consisting of a common DSF. Furthermore, the pulsewidths of the converted pulses can be maintained and even compressed after wavelength conversion. In our paper, CW light waves are applied because 


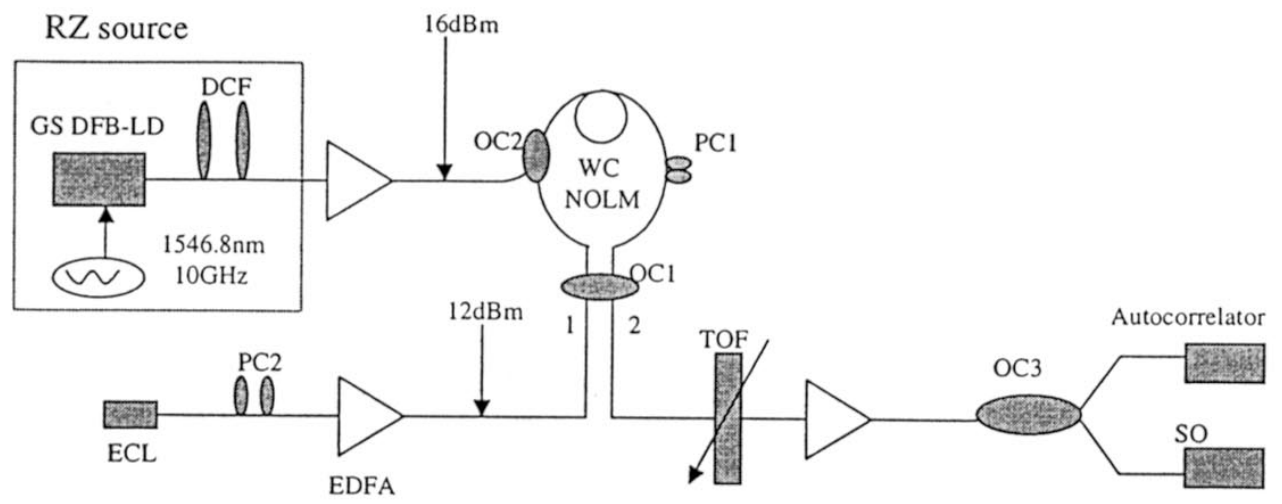

Fig. 5. Experimental setup. GS DFB-LD: gain-switched DFB laser diode. OC: optical coupler. EDFA: erbium-doped fiber amplfier. WC-NOLMP: wavelength conversion-NOLM. PC: polarization controller. TOF: tunable optical filter. ECL: external-cavity laser. DCF: dispersion compensated fiber. SO: sampling oscilloscope with 32-GHz bandwidth O-E conversion.

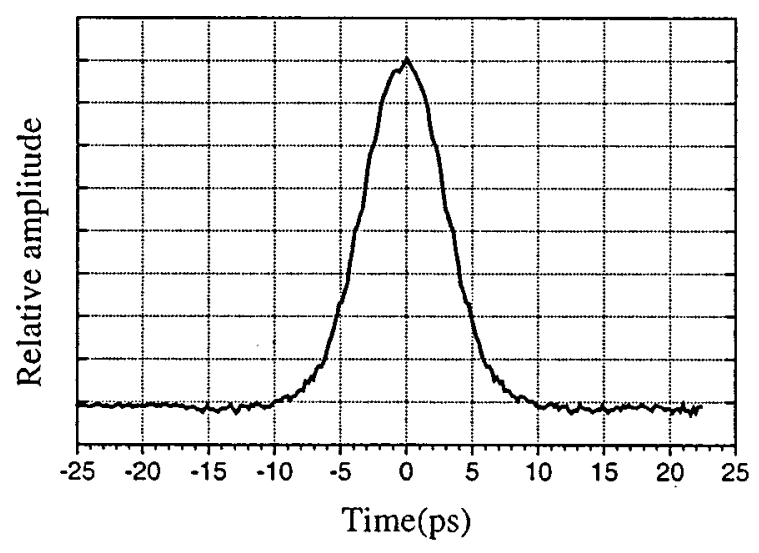

(a)

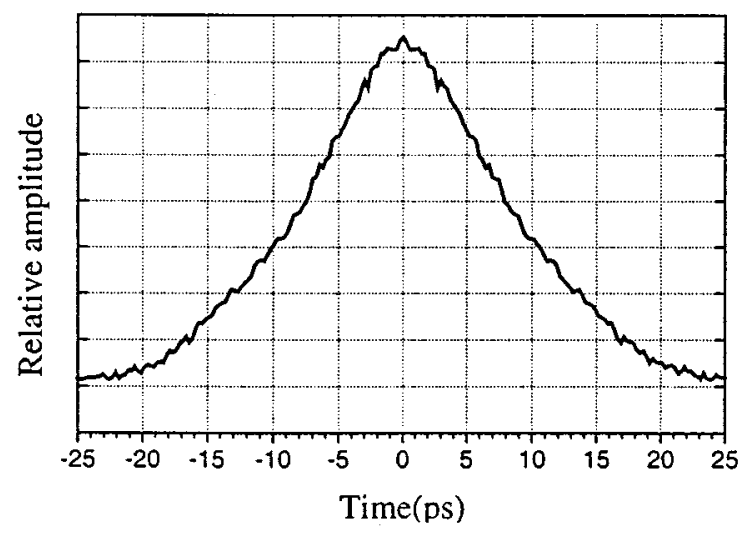

(b)

Fig. 6. Measured autocorrelator traces of converted pulses. (a) 1552 and (b) $1565 \mathrm{~nm}$.

costly electronic or optical synchronization between clock pulses and control signals is then unnecessary.

\section{A. Numerical Simulation}

The propagation of the control pulses and the copropagating and counter propagating waves in the $3 \mathrm{~km}$ DSF is governed by the nonlinear Schrödinger equation (NLSE) [25], [26]. Group velocity dispersion (GVD), self-phase modulation (SPM), and XPM are incorporated into our model. When the optical pulses are converted to longer wavelengths than the wavelength of the control pulse, the Raman effect is also included in our model, and the Raman gain profile for silica fiber was approximated as a cubic spline [26]. According to [14], the XPM effect between the control pulses and the counter propagating CW lightwave can be neglected because of the small duty cycle of the control pulses and the peak power of the control pulses being far larger than their average power.

The propagation of the three waves in the fiber loop [11], control pulses, copropagating CW lightwave and counterpropagating CW lightwave can be expressed by the following coupled NLSE's [26].
Control pulses:

$$
\begin{aligned}
& \frac{\partial A_{1}}{\partial z}+\frac{1}{\nu_{1}} \frac{\partial A_{1}}{\partial t}+\frac{i}{2} \beta\left(\lambda_{1}\right) \frac{\partial^{2} A_{1}}{\partial t^{2}}+\frac{1}{2} \alpha A_{1} \\
& \quad=i \gamma_{1}\left[\left|A_{1}\right|^{2}+2\left|A_{2}\right|^{2}\right] A_{1}-\left[\frac{g_{12}}{2}\left|A_{2}\right|^{2}\right] A_{1} .
\end{aligned}
$$

Copropagating wave:

$$
\begin{aligned}
& \frac{\partial A_{2}}{\partial z}+\frac{1}{\nu_{2}} \frac{\partial A_{2}}{\partial t}+\frac{i}{2} \beta\left(\lambda_{2}\right) \frac{\partial^{2} A_{2}}{\partial t^{2}}+\frac{1}{2} \alpha A_{2} \\
& \quad=i \gamma_{2}\left[2\left|A_{1}\right|^{2}+\left|A_{2}\right|^{2}\right] A_{2}+\left[\frac{g_{12}}{2}\left|A_{1}\right|^{2}\right] A_{2} .
\end{aligned}
$$

Counterpropagating wave:

$$
\begin{aligned}
& \frac{\partial A_{3}}{\partial z}+\frac{1}{\nu_{2}} \frac{\partial A_{3}}{\partial t}+\frac{i}{2} \beta\left(\lambda_{2}\right) \frac{\partial^{2} A_{3}}{\partial t^{2}}+\frac{1}{2} \alpha A_{3} \\
& \quad=i \gamma_{2}\left[\left|A_{3}\right|^{2}+2\left|A_{1}\right|^{2}\right] A_{3} .
\end{aligned}
$$

Here $\lambda_{i}(i=1,2)$ is the wavelength, $A_{i}(i=1,2$ and 3$)$ is the propagating optical field amplitude, $\nu_{i}$ is the group velocity, $\beta\left(\gamma_{i}\right)$ is the linear group velocity dispersion given by $-\left(\lambda_{i}^{2} D_{i} / 2 \pi c\right)$ where $D_{i}$ is the dispersion parameter, $c$ is the 


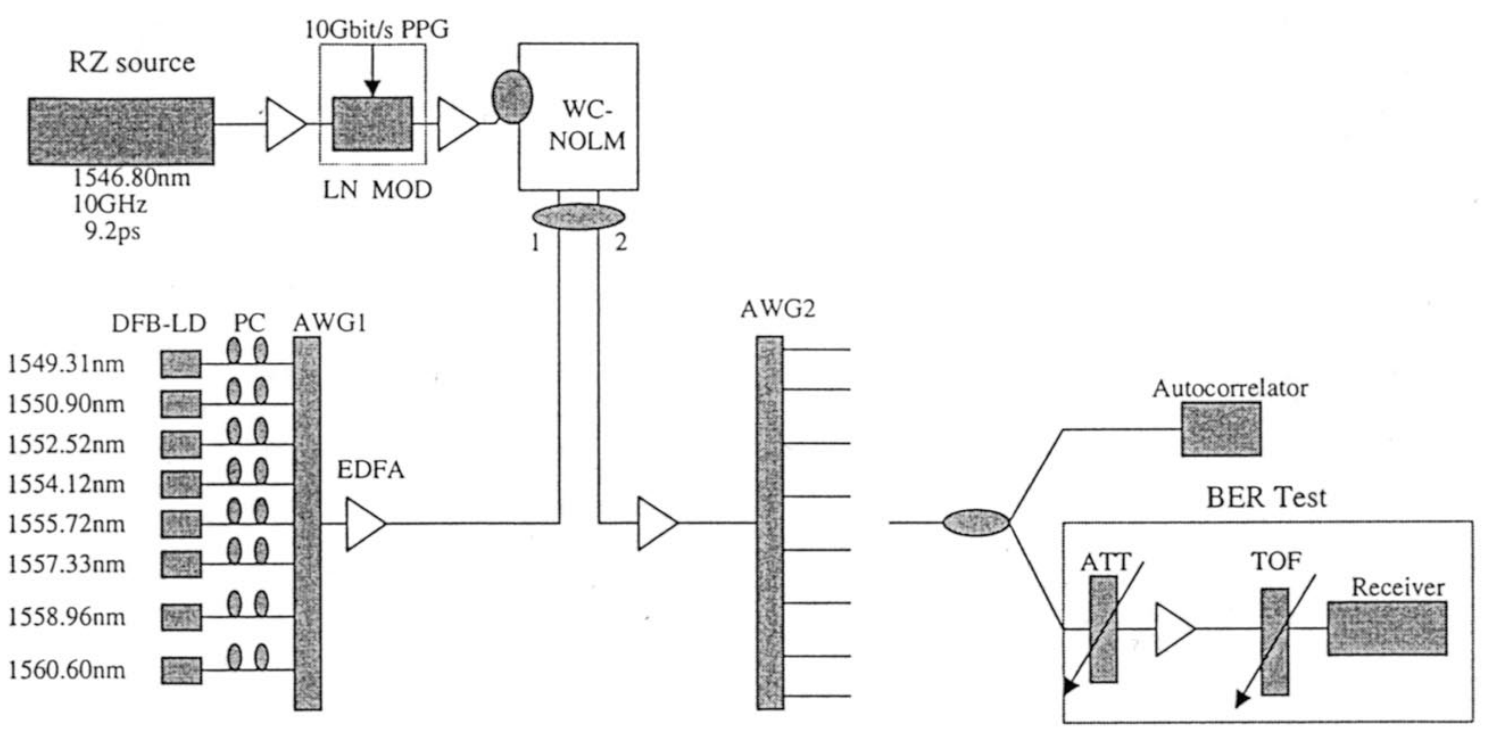

Fig. 7. Experimental setup. LN MOD: LN external modulator. AWG: arrayed waveguide grating. PPG: pulse pattern generation. ATT: attenuator. BER: bit-error rate detector. WC-NOLM: wavelength conversion NOLM. Note: The LN modulator is not used for the experiment RZ pulse conversion.

speed of light, $\gamma_{i}$ is the nonlinear coefficient defined by $\gamma_{i}=$ $n_{2} \omega_{i} / c A_{\text {eff }}=2 \pi c n_{2} / c A_{\text {eff }} \lambda_{i}$, where the nonlinear index coefficient $n_{2}=2.67 \times 10^{-20} \mathrm{~m}^{2} / \mathrm{W}$, and $A_{\text {eff }}$ is the effective fiber core area. $A_{\mathrm{eff}}=50 \mu \mathrm{m}^{2} . g_{12}$ is the Raman gain coefficient between the control pulses and the copropagating $\mathrm{CW}$ lightwave. $\alpha$ is the loss of the DSF, and we assume that it is independent of wavelength. $\alpha=0.25 \mathrm{~dB} / \mathrm{km}$. The FWHM pulsewidth, center wavelength, repetition frequency and peak power of control pulses are $8.2 \mathrm{ps}, 1546.8 \mathrm{~nm}, 10 \mathrm{GHz}$, and 150 $\mathrm{mW}$, respectively. The shape of the control pulse is Gaussian. The wavelength of the CW lightwave is changed from 1533 $\mathrm{nm}$ to $1569 \mathrm{~nm}$ while the average powers of copropagating and counter propagating CW lightwaves are both $4 \mathrm{~mW}$. The DSF total dispersion and relative group delay are shown in Fig. 1.

Fig. 2 shows numerical simulation waveforms of the converted pulses at the wavelengths of 1552 and $1565 \mathrm{~nm}$. The pulse shape becomes asymmetric and broad because of a large walkoff when the wavelength of the CW lightwave is $1565 \mathrm{~nm}$ [26]. Fig. 3 shows the FWHM pulsewidths (experimental and calculated) of the converted signals as a function of the $\mathrm{CW}$ wavelengths. From Fig. 3 we can see that the experimental pulsewidths of the converted pulses with wavelengths from 1542 to $1563 \mathrm{~nm}$ are compressed compared to control pulse. Within this wavelength range, there is a small walkoff and small dispersion, so XPM is the main effect. Assuming that the shape of the control pulse is Gaussian, when only XPM effect is considered, the power of the converted pulses can be expressed by the following equation [14], [15]:

$$
P_{\text {out }}=\frac{P_{2}}{2}\left[1-\cos \left(2 \gamma_{1} P_{1} L \exp \left(-\frac{t^{2}}{t_{c}^{2}}\right)\right)\right] .
$$

Here $L$ is the length of DSF, $P_{1}$ and $P_{2}$ are the peak power of control pulses and the power of the CW lightwave, respectively. $t_{c}$ is the pulsewidth of the control pulses which is related to the FWHM pulsewidth by FWHM $\approx 1.665 t_{c}$.

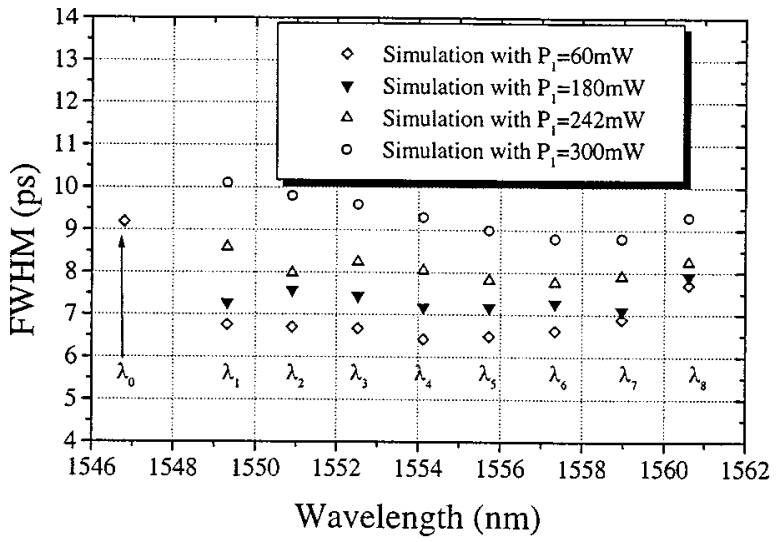

(a)

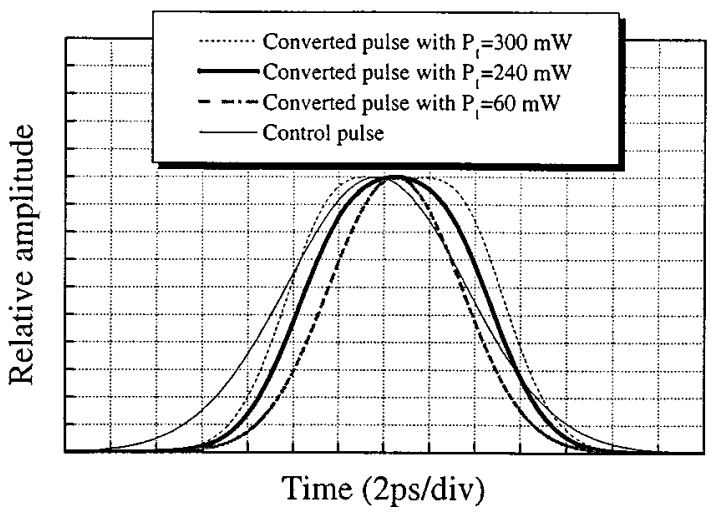

(b)

Fig. 8. Numerical simulation results with control pulsewidth of $9.2 \mathrm{ps}$ and different control power $\left(P_{1}\right)$. (a) FWHM at eight wavelengths and (b) the $\lambda_{1}$ waveform for different control peak powers.

With only XPM effect considered, Fig. 4 shows the waveforms obtained from (4). It is clearly seen that the converted pulsewidth depends on the peak power of the control pulses. 


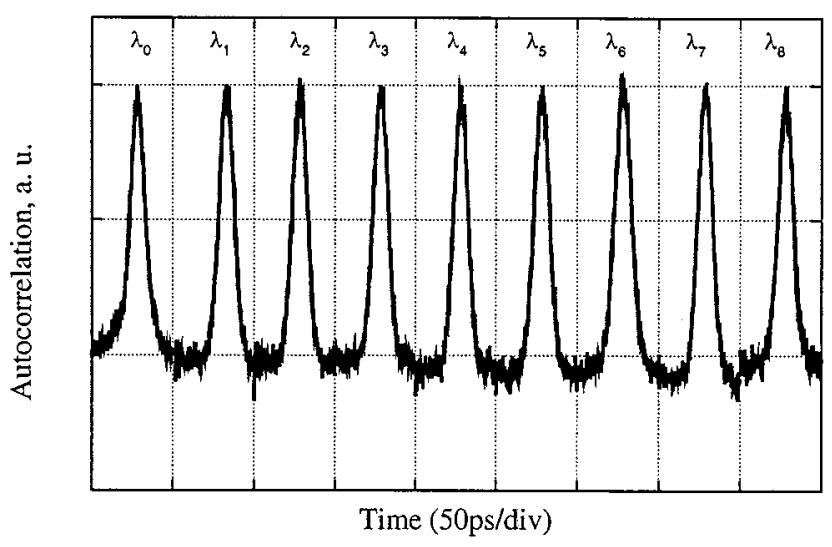

(a)

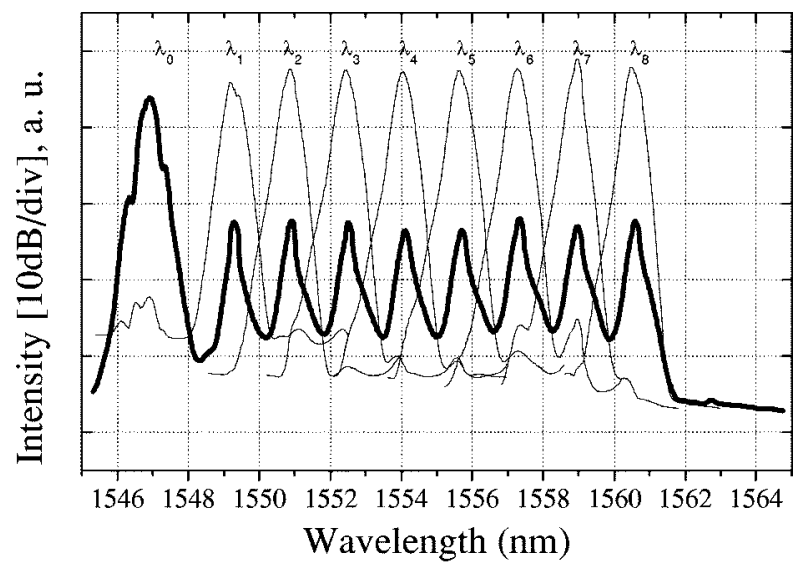

(b)

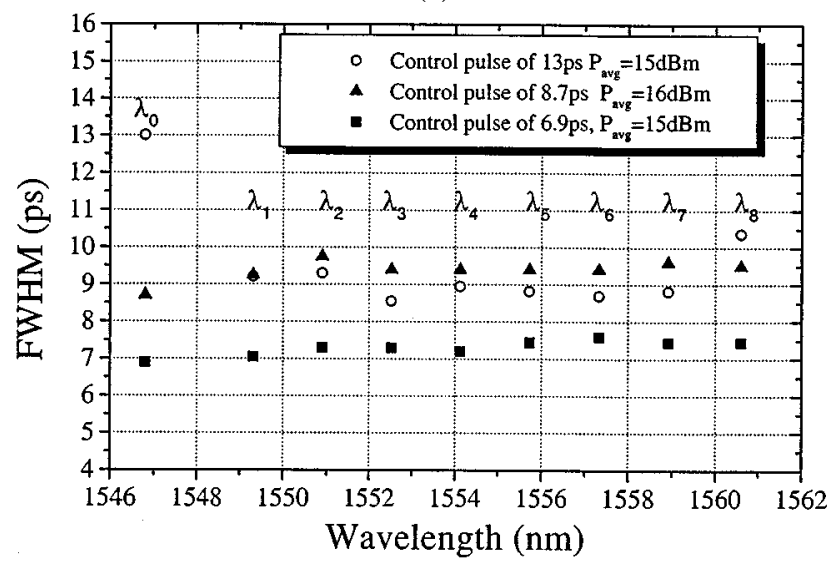

(c)

Fig. 9. Experimental results, $\lambda_{0}$ represents control pulse. (a) Autocorrelation waveform for control pulse of 8.7 ps. (b) Optical spectrum for control pulse of $8.7 \mathrm{ps}$, the thick and thin curves represent the optical spectrum from Port 2 before AWG2 filter and after AWG2 filter, respectively. (c) Pulse FWHM for different control pulsewidths and the average powers $\left(P_{\text {avg }}\right)$.

When the peak power of the control pulses is smaller than $242 \mathrm{~mW}$, the converted pulses are compressed. When the peak power of the control pulse is larger than $242 \mathrm{~mW}$, the converted pulses will be split and the pulsewidths will be broadened. With only XPM effect considered, the peak power of the control pulse for the conversion efficiency [19] of 1 is $242 \mathrm{~mW}$. It should be pointed out that the peak power of the control pulse for conversion efficiency of 1 will be larger than $242 \mathrm{~mW}$ if also

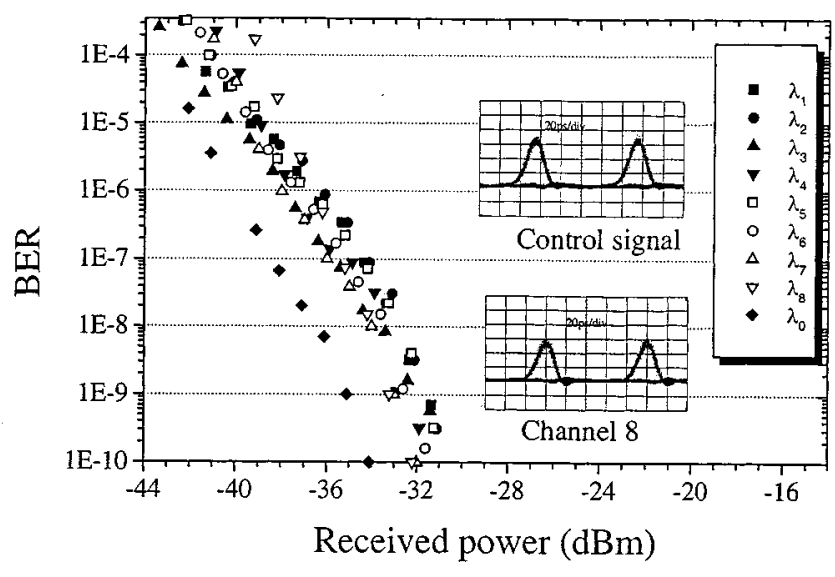

Fig. 10. BER versus received power with control pulsewidth of $8.7 \mathrm{ps}, \lambda_{0}$ represents control signal.

other effects are taken into account [19]. Because XPM effect is independent of the converted wavelengths, the pulsewidths at different converted wavelengths will be the same when only XPM effect is considered. Our numerical simulation shows that SPM and Raman effects only have a small influence on the pulsewidths of the converted pulses. When the wavelength of the $\mathrm{CW}$ lightwave is increased to a certain value, dispersion effect and walkoff effect can no longer be ignored. In such cases the converted pulsewidths will be quickly broadened as shown in Fig. 3.

\section{B. Wavelength Conversion Experiments with Single Wavelength Pulses}

The experimental diagram is shown in Fig. 5. The control laser is a $10-\mathrm{GHz}, 1546.8-\mathrm{nm}\left(\lambda_{0}\right)$ gain-switched distributed feedback laser diode (DFB LD) that generates 8.2-ps (FWHM) pulses after compression in a dispersion compensated fiber (DCF). The on-off ratio [21] between maximum and minimum transmission of the NOLM is $30 \mathrm{~dB}$ without the control signal when the state of polarization controller 1 is varied. The $\mathrm{CW}$ lightwave is generated by a tunable external cavity laser. The control signal is coupled into the NOLM using a wavelength independent $3 \mathrm{~dB}$ optical coupler (OC2). Polarization controller 1 in the loop is used to obtain best performance of the converted pulses. A 1.6-nm bandpass tunable optical filter (TOF) at the output of the NOLM is used to suppress the control pulses. The average power of the control pulses into the $3 \mathrm{~dB}$ OC2 is $16 \mathrm{dBm}$, and the power of the $\mathrm{CW}$ lightwave into $\mathrm{OC} 1$ is $12 \mathrm{dBm}$. All OC's are $2 \times 2$ couplers with power coupling ratios of $50: 50 \%$. The length of the DSF in the NOLM for wavelength conversion (WC-NOLM) is $3 \mathrm{~km}$. We measured the total group delay and dispersion of the DSF in the WC-NOLM. The results are shown in Fig. 1. It is a common DSF with zero dispersion wavelength of $1550.7 \mathrm{~nm}$ and dispersion slope of $0.08 \mathrm{ps} / \mathrm{nm}^{2} / \mathrm{km}$.

The pulse traces are measured by an autocorrelator and the measured results are shown in Fig. 6. Assuming that the waveforms of the converted pulses have Gaussian shapes, then the FWHM pulsewidths are equal to the second harmonic generation (SHG) trace pulsewidths divided by 1.414 . Of course, the 


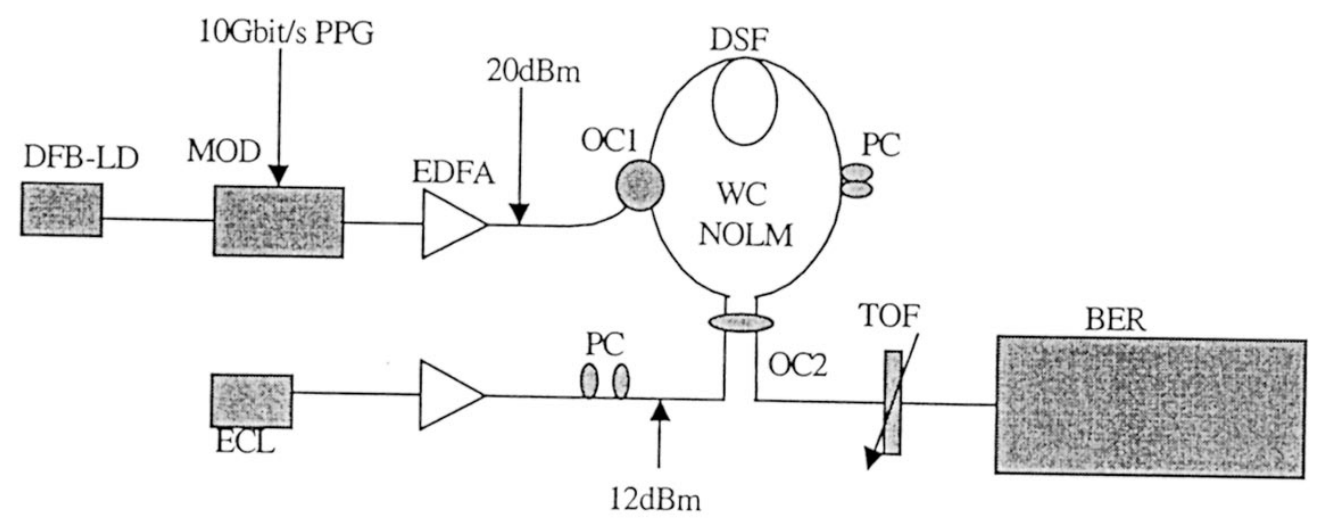

Fig. 11. Experimental Setup.

results will not be accurate when the pulse shape of the converted pulse is not Gaussian. So there is a considerable difference between the numerical simulation and experimental results when the wavelength separation between the control pulse and the CW lightwave is large. However, the numerical simulation and experimental results are in good agreement when the wavelength separation is small. Some typical autocorrelator traces are shown in Fig. 6. Because of the large walkoff, the pulses at $1565 \mathrm{~nm}$ are broadened severely.

\section{Experiments with Wavelength Conversion into Multiwavelength Pulses}

Broadband low-noise optical sources are of vital importance for future large-capacity flexible optical network utilization of both OTDM and WDM [20]-[22]. It is an effective method to generate short pulses by using supercontinuum, but a dispersion-flattened fiber and a special WDM filter for filtering the channels will be needed [20]-[22].

From Fig. 3, we can see that almost equal pulsewidths at different wavelengths are obtained when the wavelength separation between the control pulses and the CW lightwave is small. In this section, simultaneous RZ pulses at eight different wavelengths are realized by using wavelength conversion in an NOLM consisting of a common DSF. The NOLM for wavelength conversion is the same as that in the above section. The converted wavelengths of the eight signal pulses are in agreement with the ITU-T proposal (200 GHz spacing) and a commercial arrayed-waveguide grating (AWG) is used to realize demultiplexing in the frequency-domain. The converted pulses at the different wavelengths have nearly equal widths and same amplitudes.

The experimental setup is shown in Fig. 7. The outputs of eight commercial DFB lasers are multiplexed in a commercial AWG having a wavelength spacing of $1.6 \mathrm{~nm}$ (it can be substituted by an $8 \times 1$ optical coupler). These lasers operate according to the ITU-standardized wavelength proposal. The operating wavelengths are $1549.31 \mathrm{~nm}\left(\lambda_{1}\right), 1550.90 \mathrm{~nm}\left(\lambda_{2}\right)$, $1552.52 \mathrm{~nm}\left(\lambda_{3}\right), 1554.12 \mathrm{~nm}\left(\lambda_{4}\right), 1555.72 \mathrm{~nm}\left(\lambda_{5}\right), 1557.33$ $\mathrm{nm}\left(\lambda_{6}\right), 1558.96 \mathrm{~nm}\left(\lambda_{7}\right)$ and $1560.60 \mathrm{~nm}\left(\lambda_{8}\right)$. The combined signals of the eight channels are amplified to an average power of $18 \mathrm{dBm}$, and injected into the NOLM from Port 1 . The control laser is a $10 \mathrm{GHz}, 1546.8 \mathrm{~nm}\left(\lambda_{0}\right)$ gain-switched DFB LD that generates 6.0-13.0 ps (FWHM) pulses after compression in a DCF. In order to get different pulsewidths of the converted signal, the average power of the control pulses is adjustable (13 to $18 \mathrm{dBm}$ ). The $\mathrm{RZ}$ pulses at eight wavelengths are realized simultaneously by using wavelength conversion in the NOLM. Fig. 8 shows the numerical simulation results with the control pulsewidth of $9.2 \mathrm{ps}$ and different peak power of the control pulses. From Fig. 8(a) we can see that the converted pulsewidth are nearly independent of wavelengths for each control power. Fig. 8(b) shows that the converted pulsewidths are dependent on the control power.

Fig. 9 shows the experimental results. Equal amplitudes, nearly equal pulsewidths and larger than 30-dB sidemode suppression ratios at different wavelengths are obtained. From Fig. 9(c) we can see that the pulsewidths of the converted pulses can be made narrower or a little wider than that of the control pulses by changing the power and the pulsewidths of the control pulses.

After adding the LN modulator, and modulating the optical pulses with a pseudorandom bit sequence (PRBS) of $2^{31}-1$, BER's of the eight $10 \mathrm{~Gb} / \mathrm{s}$ channels are measured. The average power of the control pulses is $15 \mathrm{dBm}$. The BER curves in Fig. 10 show no error floors and the measured power penalties for $\mathrm{BER}<10^{-9}$ are all within $4 \mathrm{~dB}$. The power penalties are mainly attributed to reduced signal-to-noise ratio (SNR). From Fig. 9(b) we can see that the SNR of the converted signals is over $10 \mathrm{~dB}$ smaller than that of the control signals. Increasing the input power of the CW light into the NOLM is beneficial for SNR improvement of the converted signal, and for reducing the power penalty. Our experiment has demonstrated that the power penalty is very small and even negative when only one channel of CW light with an average power of $14 \mathrm{dBm}$ is operated [12]. The un-flattened gain of the EDFA leads to different penalties for the different channels.

\section{NRZ WAVELENGTH CONVERSION}

There are two main difficulties with NRZ wavelength conversion. One is a high peak power requirement for the control pulse to obtain a high conversion efficiency. However, the duty cycle of NRZ signals is 1, and the peak power of the NRZ signals is only twice the average power. So it is difficult to get an NRZ 


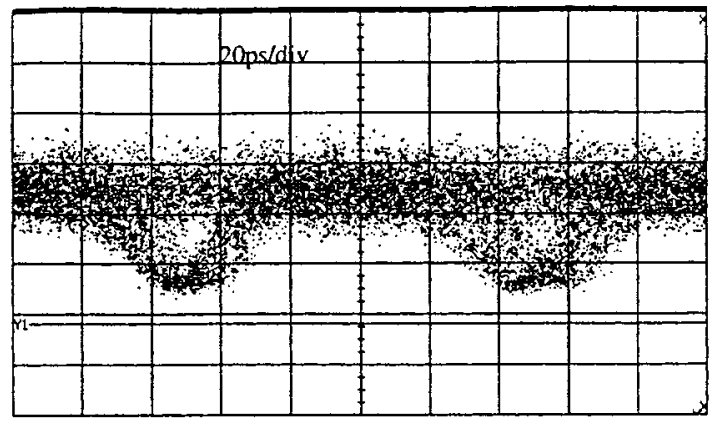

(a)

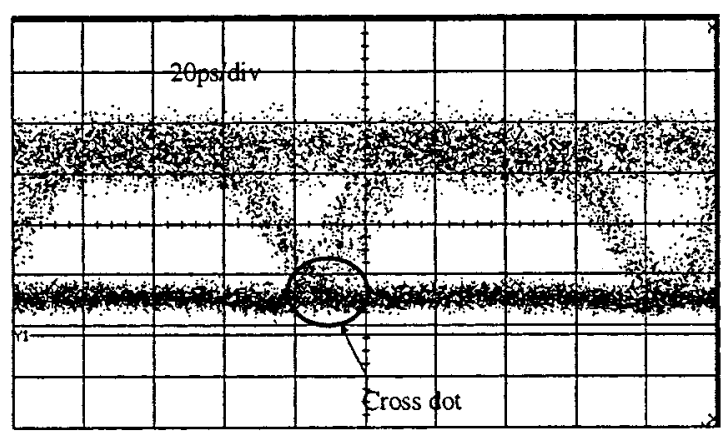

(c)

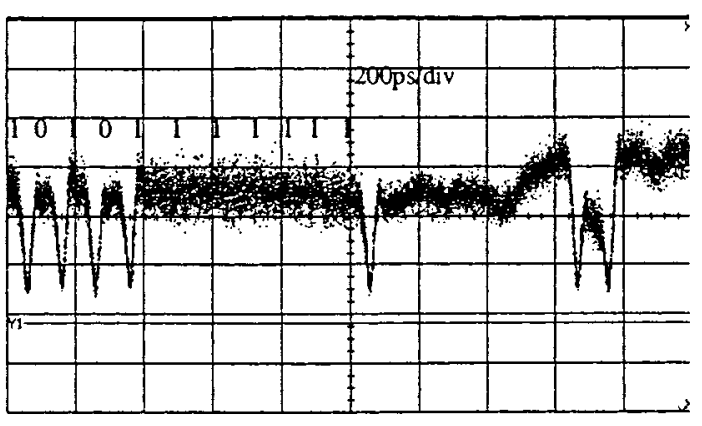

(b)

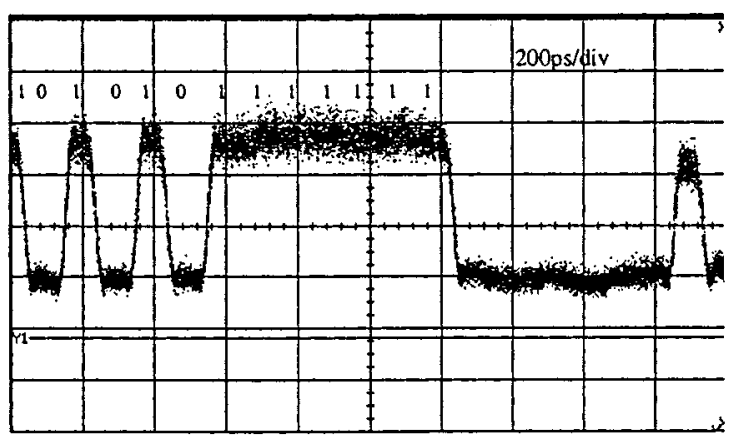

(d)

Fig. 12. (a) and (b) Eye diagram and waveform of the converted signal at $1546 \mathrm{~nm}$ without adjusting the polarization controller in the NOLM, respectively. (c) and (d) Eye diagram and waveform the converted signal at $1546 \mathrm{~nm}$ with adjusting the polarization controller in the NOLM.

pulse with a high peak power because of the finite average power of EDFA output. Another problem is that the counter propagating signal waves will generate a large unwanted nonlinear phase shift, which will lead to a poor extinction ratio (ER) of the converted pulses. Reference [11] has shown that the unwanted nonlinear phase shift of the counter propagating wave can be compensated by adjusting the state of polarization controller in the NOLM. Our experiment will confirm this observation, and $10-\mathrm{Gb} / \mathrm{s}$ NRZ wavelength conversion based on a NOLM is achieved for the first time.

\section{A. Experiment}

The experimental setup is shown in Fig. 11. The WC-NOLM is the same as that in Fig. 7. The control signal with the center wavelength of $1556 \mathrm{~nm}$ is externally modulated by a LN modulator to $10 \mathrm{~Gb} / \mathrm{s}$ using a PRBS of $2^{11}-1$. The control signal is coupled into the NOLM using OC1. The CW lightwave from an external cavity laser is injected into the NOLM using OC2. A 1.6-nm bandpass filter at the output of the NOLM is used to suppress the control signal. The average power of the control signal into $\mathrm{OC} 1$ is $20 \mathrm{dBm}$, and that of the $\mathrm{CW}$ lightwave into OC2 is $12 \mathrm{dBm}$. In this experiment, the range of the tunable optical filter (TOF) is from 1530 to $1561 \mathrm{~nm}$.

\section{B. Results and Discussions}

In order to obtain maximum nonlinear phase shift between the control signal and the co-propagating wave, we assume that

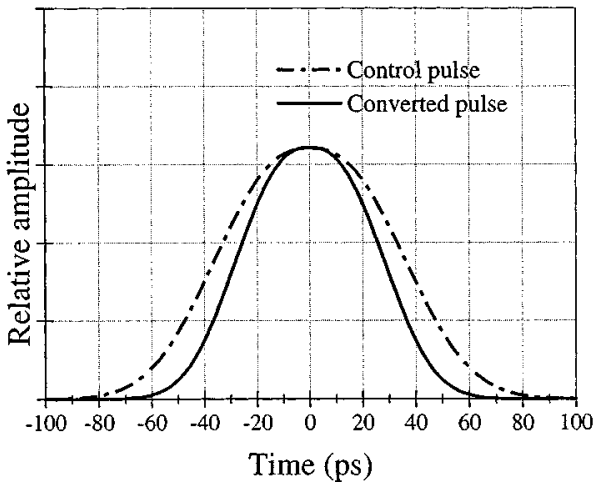

Fig. 13. Calculated pulse waveform with only XPM considered and $P_{1}=100$ $\mathrm{mW}$.

they have parallel polarization. According to Ref. [11], ER of the converted signal can be written as

$$
\mathrm{ER}=\frac{\sin ^{2}\left(\left(\hat{\Phi}_{\mathrm{co}}-\left(\Phi_{\mathrm{cn}}-\Phi_{\mathrm{cn}, 0}\right)\right) / 2\right)}{\sin ^{2}\left(\left(\Phi_{\mathrm{cn}}-\Phi_{\mathrm{cn}, 0}\right) / 2\right)} .
$$

Here $\hat{\Phi}_{\text {co }}$ and $\Phi_{\text {cn }}$ denote the maximum phase shift of the copropagating wave and phase shift of the counterpropagating wave produced by XPM from the control signal, respectively. $\Phi_{\mathrm{cn}, 0}$ denotes the fixed phase shift of the counter propagating signal caused by the polarization controller in the NOLM. 


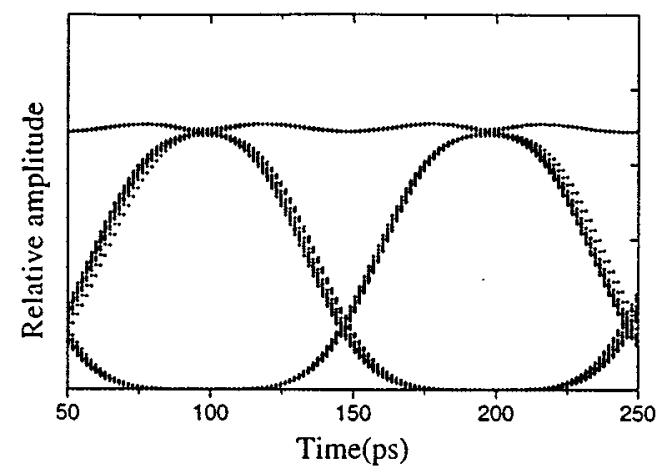

(a)

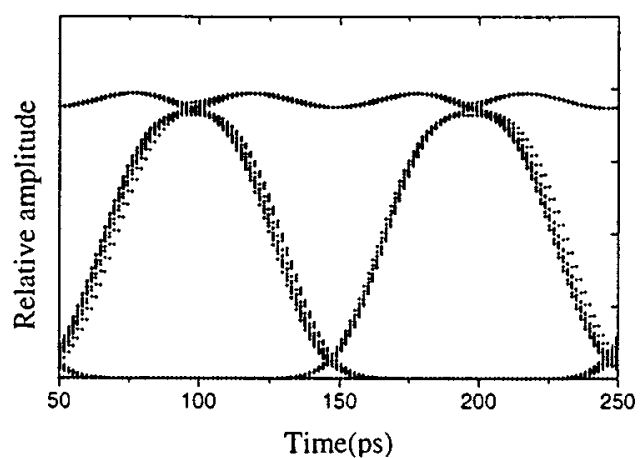

(b)

Fig. 14. Eye diagrams of numerical simulation. (a) Control signal $(1556 \mathrm{~nm})$. (b) Converted signals $(1546 \mathrm{~nm})$.

Without considering GVD and SPM in the DSF, and assuming no walk-off between control pulses and signal pulses, and if polarization between counter propagating $\mathrm{CW}$ lightwave and control signal is parallel, then $\Phi_{\mathrm{cn}, 0}=0 . \hat{\Phi}_{\mathrm{co}}$ can be expressed as $2 \gamma_{1} P_{1} L$ [11], [14], and $\Phi_{\mathrm{cn}}$ can be expressed as $\gamma_{1} P_{1} L$ when there is equal distribution of " 1 "s and " 0 "s in the control pulse train [11], [14], here $P_{1}$ is the peak power of the control pulse, $L$ is the length of the DSF and $\gamma_{1}$ is the nonlinear coefficient of the fiber. In this case, according to (5), the ER of the converted signal is one, and Fig. 12(a) and (b) shows, respectively, the optical eye diagram and the waveform of the converted signal for the center wavelength of the control signal of $1556 \mathrm{~nm}$. We can see that there is nearly no difference between the " 1 "s and " 0 "s, and the eye is almost closed.

According to (5), in order to obtain high ER of the converted signal, we must find a proper $\Phi_{\mathrm{cn}, 0}$ to make $\Phi_{\mathrm{cn}}=\Phi_{\mathrm{cn}, 0}$. It means that $\Phi_{\mathrm{cn}}=\beta \gamma_{s} P_{0} L / 2=\Phi_{\mathrm{cn}, 0} \cdot \beta$ represents the XPM parameter between the counter propagating wave and the control signal and it ranges from $2 / 3$ to 2 [26]. Fig. 12(c) and (d) shows, respectively, the eye diagram and the waveform of the converted signal after adjusting the polarization state of polarization controller in the NOLM. We can see that there is a high ER of the converted signal. It demonstrates that the nonlinear phase shift of the counterpropagating wave can be compensated by adjusting the state of polarization controller in the NOLM.

Observing Fig. 12(c), we can see that the cross dot is moved to a very deep position. The reason is that the width of "mark" is compressed. Assuming the control pulse to be a super Gaussian pulse with a sharpness figure of 1.436 [26], the nonlinear phase shift of counterpropagating wave is compensated by adjusting polarization controller in the NOLM, and only considering XPM effect, the output of the converted pulse can be expressed as

$$
P_{\text {out }}=P_{2}\left[1-\cos \left(2 \gamma_{1} P_{1} L \exp \left(-\left(\frac{t}{t_{c}}\right)^{2.872}\right)\right)\right] .
$$

The meaning of symbols in (6) is the same as that in (4). $t_{c}=44.6 \mathrm{ps}$. The waveforms of the pulses obtained from (6) are shown in Fig. 13. It is clearly seen that the converted pulse is compressed. Fig.14 shows the numerical simulation results

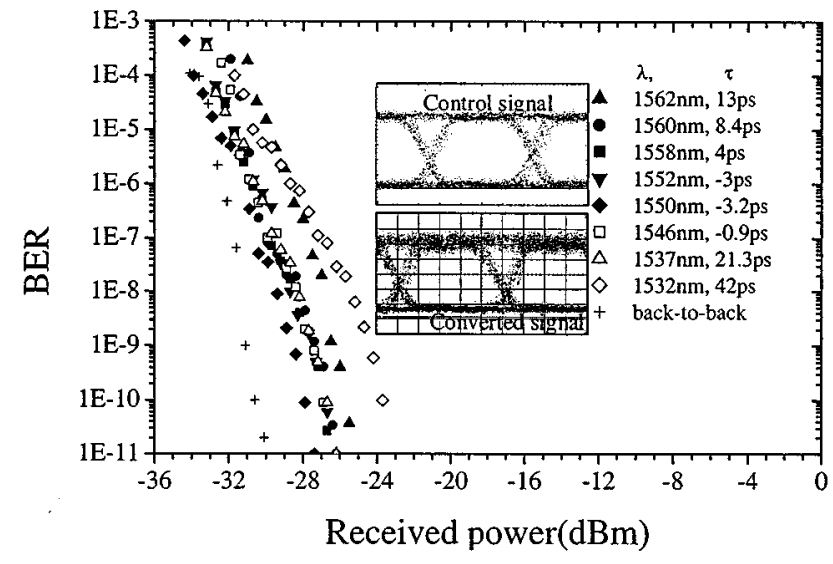

Fig. 15. BER versus received power. $\tau$ represents the walkoff time between the control signal and CW lightwave. The insets are the eye diagrams of the control signal and the converted signal $(1560 \mathrm{~nm})$.

with XPM, SPM, GVD and Raman effects considered. The parameters for the numerical simulation are the same as those in the above experiment. From Fig. 14, we can see that the cross dot is moved to a low position and that is in good agreement with Fig. 12(c).

Fig. 15 shows the BER performance of the control signal (back-to-back) and the converted signals at different center wavelengths. The insets are the eye diagrams of the control signal and the converted signal $(1560 \mathrm{~nm})$. The maximum and minimum power penalty of the converted signals is $7 \mathrm{~dB}$ and $2.6 \mathrm{~dB}$, respectively. We can see that there is no error floor for the converted signals at the different wavelengths. Fig.16 shows the eye diagrams of numerical simulation of converted signals at $1532 \mathrm{~nm}$ and $1562 \mathrm{~nm}$ without considering ASE noise of EDFA's. Our numerical simulation shows that when the wavelengths of the $\mathrm{CW}$ light is chosen to be from 1537 to 1560 $\mathrm{nm}$, the converted eye diagrams have no obvious difference, because the walkoff time and dispersion within this wavelength range are not very large; XPM is the main effect, and XPM is independent of wavelength. So, the power penalties of the converted signals should be equal. In our experiment, the polarization controller in the NOLM plays an important role because 


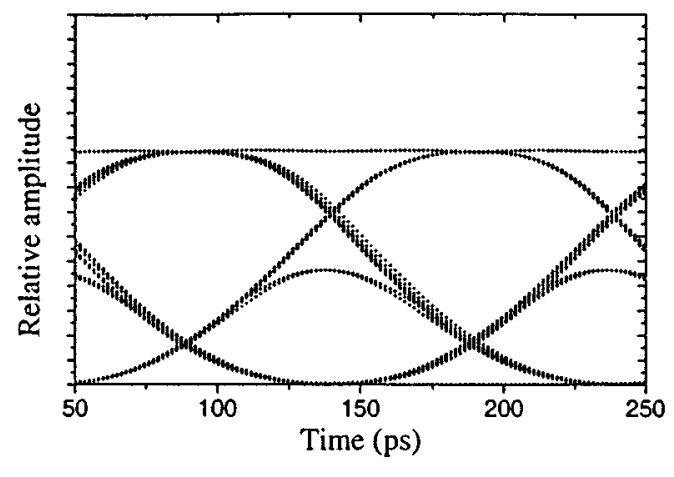

(a)

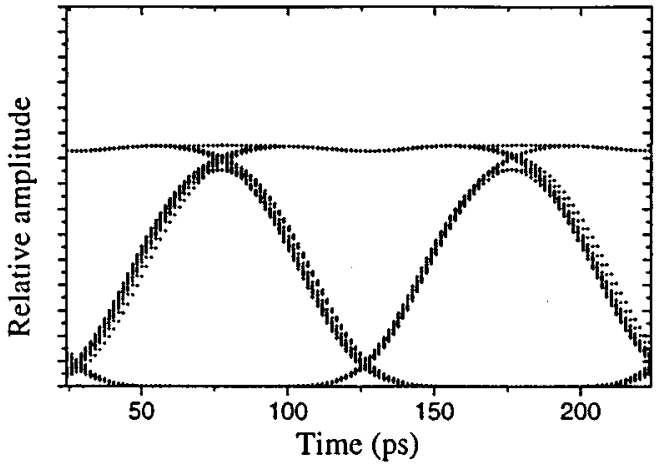

(b)

Fig. 16. Eye diagrams of numerical simulation of converted signals without considering ASE noise of EDFA's (a) 1532 and (b) $1562 \mathrm{~nm}$.

ER improvement is realized by adjusting the polarization state of the polarization in the NOLM. However, considering the precision in adjusting the polarization controller in the NOLM and the fluctuation in the states of polarization in the fibers, an error in the power penalty might exist at each BER curve. Therefore, a maximum difference of approximately $1 \mathrm{~dB}$ in power penalty between different channels is shown in Fig. 15 when the wavelengths are chosen to be from $1537 \mathrm{~nm}$ to 1560 $\mathrm{nm}$.

When the wavelength of the CW light is chosen to be 1532 nm, we can see from Fig. 15 that the converted signals have about $7 \mathrm{~dB}$ power penalty. We believe the power penalty is mainly caused by the following two factors. First, large walkoff will lead to an obvious intersymbol interference (ISI), which can be observed in Fig. 16(a), and the ISI will in turn lead to some power penalty. Second, because all EDFA's in our experiment are common EDFA's, we can see from Fig. 17 that the noise figure of the EDFA used to amplify the CW light is very large when the wavelength is $1532 \mathrm{~nm}$ and which large ASE noise of EDFA leads to the converted signals having a small SNR, in turn will increase the power penalty.

When the CW light wavelength is $1562 \mathrm{~nm}$, from Fig. 16(b), no obvious ISI can be observed, but $1562 \mathrm{~nm}$ is a little beyond the range of the TOF. So the converted signals after the TOF are distorted and this leads to a little larger penalty.

The optical receiver output depends on the input pulse shape and pulsewidth, so pulse shapes and pulsewidths of the converted signals will also have some effect on the power penalty. When properly increasing the length of the DSF or the output power of EDFA3, the power penalties of the converted signals will be reduced. In order to obtain the conversion efficiency of 1 , the requirement for the peak power of the control signals should be $242 \mathrm{~mW}$ (only XPM effect considered). However, in our experiment, we can only obtain $100 \mathrm{~mW}$ for the peak power of the control signals.

\section{CONCLUSION}

Wavelength conversion of short pulses at $10 \mathrm{GHz}$ based on an NOLM has been experimentally and numerically investigated. With small walkoff between the control pulses and the CW light-

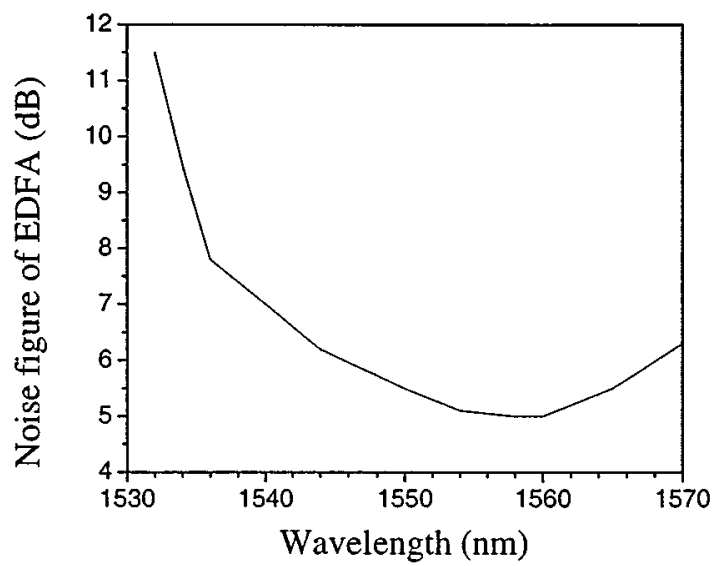

Fig. 17. Measured noise figure of EDFA used to amplify the CW light with an input power of $-3 \mathrm{dBm}$.

waves and small GVD, the pulsewidths of the converted pulses are dependent on the power of the control pulses. Furthermore, the converted pulsewidths at different wavelengths are nearly the same. Because the pulsewidths of the converted signals can be maintained and even compressed, the converted signals will be suitable for RZ based networks.

An eight-wavelength RZ optical source having high sidemode suppression ratios, equal amplitudes and almost the same pulsewidths using wavelength conversion in a NOLM consisting of a common DSF is demonstrated. The converted wavelengths of the eight channels adhere to the ITU-T proposal, and the demultiplexing in the frequency-domain is realized by a common commercial AWG.

NRZ wavelength conversion at $10 \mathrm{~Gb} / \mathrm{s}$ based on a NOLM has been demonstrated. We have experimentally confirmed that the nonlinear phase shift of the counter propagating wave can be compensated by adjusting the state of polarization controller in the NOLM and converted signals with high ER can be obtained.

\section{ACKNOWLEDGMENT}

The authors would like to gratefully acknowledge Lucent Technological Denmark and France Telecom CNET for pro- 
viding, respectively, the optical fibers and the gain-switched laser used in this work.

\section{REFERENCES}

[1] A. Jourdan, F. Masetti, M. Garnot, G. Soulage, and M. Sotom, "Design and implementation of a fully recongurable all-optical crossconnect for high capacity multi-wavelength transport networks," J. Ligthwave Technol., vol. 14, no. 6, pp. 1198-1206, 1996.

[2] P. E. Green, L. A. Coldren, K. M. Johnson, J. G. Lewis, C. M. Miller, J. F. Morrision, R. Olshansky, R. Ramaswami, and E. H. Smith, "Alloptical packet-switched metropolitan-area network proposal," J. Ligthwave Technol., vol. 11, pp. 745-763, May 1996.

[3] J. M. Wiesenfeld, B. Glance, J. S. Perino, and A. H. Gnauck, "Wavelength conversion at $10 \mathrm{Gbit} / \mathrm{s}$ using a semiconductor optical amplifier," IEEE Photon. Technol. Lett., vol. 5, pp. 1300-1303, Nov. 1993.

[4] C. Joergensen, S. L. Danielsen, and M. Vaa et al., " $40 \mathrm{Gbit} / \mathrm{s}$ all-optical wavelength conversion by semiconductor optical amplifiers," Electron. Lett., vol. 32, no. 4, pp. 367-368, 1996.

[5] T. Fjelde, D. Wolfson, P. B. Hansen, A. Kloch, C. Janz, A. Coquelin, I. Guillemot, F. Gaborit, F. Poingt, B. Dagens, and M. Renaud, " 20 Gbit/s optical wavelength converison in all-active Mach-Zehnder interferometer," Electron. Lett., vol. 35, no. 11, pp. 913-914, 1999.

[6] B. Mikkelsen, M. Vaa, H. N. Poulsen, S. L. Danielsen, C. Joergensen, A. Kloch, A. P. B. Hansen, K. E. Stubkjaer, K. Wunstel, K. Daub, E. Lach, G. Laube, W. Idler, M. Schilling, and S. Bouchoule, " 40 Gbit/s alloptical wavelength converter and RZ-NRZ format adapter realized by monolithic integrated active Michelson interferometer," Electron. Lett., vol. 33, no. 2, pp. 133-134, 1997.

[7] S. Y. Set, R. Girardi, and E. Riccardi, " $40 \mathrm{Gbit} / \mathrm{s}$ field transmission over standard fiber using midspan spectral inversion for dispersion compensation," Electron. Lett., vol. 35, no. 7, pp. 581-582, 1997.

[8] M. F. C. Stephens, D. Nesset, R. V. Penty, I. H. White, and M. J. Fice, "Wavelength conversion at $40 \mathrm{Gbit} / \mathrm{s}$ via four wave mixing in semicondutor optical amplifier with integrated pump laser," Electron. Lett., vol. 35, no. 3, pp. 420-421, 1999.

[9] A. E. Kelly, D. D. Marcenac, and D. Nesset, " $40 \mathrm{Gbit} / \mathrm{s}$ wavelength conversion over $24.6 \mathrm{~nm}$ using FWM in a semiconductor optical amplifier with an optimized MQW active region," Electron. Lett., vol. 33, no. 25, pp. 2123-2124, 1997.

[10] S. Watanabe, S. Takeda, G. Ishikawa, H. Ooi, J. G. Nielsen, and C. Sonne, "Simultaneous wavelength conversion and optical phase conjugation of $200 \mathrm{Gbit} / \mathrm{s}(5 \times 40 \mathrm{Gbit} / \mathrm{s})$ WDM signal using a highly nonlinear fiber four-wave mixing," in Proc. ECOE'97, 1997, Paper TH3A1-4, pp. 1525-1529.

[11] C. Kolleck and U. Hempelmanann, "All optical wavelength conversion of NRZ and RZ signals using a nonlinear optical loop mirror," J. Lightwave Technol., vol. 15, pp. 1906-1913, Oct. 1997.

[12] J. Yu, X. Zheng, F. Liu, A. Buxens, and P. Jeppesen, "Simultaneous realization wavelength conversion and signal regeneration using nonlinear optical loop mirror," Opt. Commun., vol. 175, pp. 173-177.

[13] K. A. Rauschenbach, K. L. Hall, J. C. Livas, and G. Raybon, "All-optical pulse width and wavelength conversion at $10 \mathrm{Gbit} / \mathrm{s}$ using a nonlinear optical loop mirror," IEEE Photon. Technol. Lett., vol. 6, no. 9, pp. 1130-1132, 1994

[14] M. Jinno, "All optical signal regularizing/regeneration using a nonlinear fiber Sagnac interferometer switch with signal-clock walk-off," J. Lightwave Technol., vol. 12, pp. 1684-1659, Sept. 1994.

[15] M. Jinno and M. Abe, "All-optical regenerator based on nonlinear fiber Sagnac interferometer," Electron. Lett., vol. 28, no. 15, pp. 1350-1352, 1992.

[16] D. L. Butler, P. S. Cho, and M. W. Chbat, "Operation of a nonlinear optical loop mirror with orthogonally polarized waves in nonploarization-preserving, single-mode fiber," IEEE Photon. Technol. Lett., vol. 8, pp. 779-781, June 1996.

[17] K. Uchiyama, T. Morioka, and M. Saruwatari, "Polarization-independent wavelength conversion using nonlinear optical loop mirror," Electron. Lett., vol. 31, no. 21, pp. 1862-1863, 1995.

[18] Y. Liang, J. W. Lou, J. C. Stocker, O. Boyraz, J. K. Andersen, and M. N. Islam, "Polarization insensitive nonlinear optical loop mirror demultiplexer using twisted fiber," in Proc. OFC'99, 1999, Paper THA31-3.

[19] W. S. Man, H. Y. Tam, and M. S. Demokan, "Optimal loop length of a nonlinear optical loop mirror in switching solitons," J. Ligthwave Technol., vol. 16, pp. 100-105, Jan. 1998.
[20] S. Kawanishi, H. Takara, K. Uchiyama, L. Shake, and K. Mori, "3 Tbit/s (160 Gbit/s $\times 19 \mathrm{ch})$ OTDM/WDM transmission experiment," in Proc. OFC'99, 1999, Postdeadline PD1.

[21] T. Morioka, K. Mori, and M. Saruwatari, "More than 100-wavelengthchannel picosecond optical pulse generation from single laser source using supercontinuum in optical fibers," Electron. Lett., vol. 29, no. 10, pp. 862-864, 1993

[22] T. Morioka, K. Uchiyama, S. Kawarishi, S. Suzuki, and M. Saruwatari, "Multi-wavelength picosecond pulse source with low jitter and high optical frequency stability based on $200 \mathrm{~nm}$ supercontinuum filtering," Electron. Lett., vol. 31, no. 10, pp. 1064-1066, 1995.

[23] K. J. Blow, N. J. Doran, and B. P. Nelson, "Demonstration of the nonlinear fiber loop mirror as an ultrafast all-optical demultiplexer," Electron. Lett., vol. 26, no. 14, pp. 962-964, 1990.

[24] P. A. Andrekson, N. A. Olsson, J. R. Simpson, D. J. Digiovanni, P. A. Morton, T. Tanbun-Ek, R. A. Logan, and K. W. Wecht, " $64 \mathrm{~Gb} / \mathrm{s}$ all-optical demultiplexing with the nonlinear optical-loop mirror," IEEE Photon. Technol. Lett., vol. 4, pp. 644-647, 1992.

[25] M. Jinno, "Effects of group velocity dispersion on self/cross phase modulation in a nonlinear Sagnac interferometer switch," J. Lightwave Technol., vol. 10, no. 8, pp. 1167-1178, 1992.

[26] G. P. Agrawal, Nonlinear Fiber Optics. New York: Academic, 1995.

Jianjun Yu was born in Hunan, China, 1968. He received the B.S. degree in optics from Xiangtan University, China, in 1990 and the M.E. and Ph.D. degrees in optical communications from Beijing University of Posts and Telecommunications, Beijing, China, in 1996 and 1999, respectively.

He joined Research Center COM, Technical University of Denmark as a Postdoctoral fellow, in June 1999, where he has been engaged in research on high speed optical communication systems and networks. Since December 1999, he has been an Assistant Research Professor in COM.

Xueyan Zheng was born in Hebei, China, in 1969. He received the Ph.D. degree from Beijing University of Posts and Telecommunications, China, in 1998 and the M.S. degree in optics from Changchun Institute of Optics and Fine Machinery, China, in 1995. He received B.S. degree in physics from Hebei Normal University, China, in 1992.

Currently, he is an Assistant Research Professor in Research Center COM at Technical University of Denmark. He has been engaged in wavelength conversion, regeneration and DWDM transmission system. He is also interested in WDM network architecture and planning.

Christophe Peucheret was born in Bar-sur-Aube, France, in 1970. He received the Diplôme d'Ingénieur from Ecole Nationale Supérieure des Télécommunications de Bretagne, Brest, France, and the M.Sc. degree in microwaves and optoelectronics from University College London, U.K., both in 1994.

Since 1997, he has been with the Department of Electromagnetic Systems, then Research Center COM at the Technical University of Denmark. His current interests are filtering effects in WDM systems and dispersion management.

Anders T. Clausen received the M.Sc.E.E. degree from the Technical University of Denmark (DTU) in 1997 from the Department of Electromagnetic Systems, now Research Center COM. In June 1999, he started at the Ph.D. degree project entitled "Experimental and theoretical investigations of systems with potential for terabit capacity."

Here, he worked from 1997 to 1999 as Research Associate at System Group funded by the European projects HIGHWAY and REPEAT. His research activities includes high-speed optical time division multiplexed systems in terms of clock-recovery (optical and electrical), synchronization, transmission, all-optical regeneration, and signal-processing. 
Henrik N. Poulsen was born in 1969 in Copenhagen, Denmark. In 1995, he received the M.Sc.E.E. degree from the Electromagnetics Institute of Technical University of Denmark, and is currently working toward the Ph.D. degree at Research Center COM at the Technical University of Denmark.

His field of interest is high bit rate signal processing in semiconductor devices, in particular all-optical techniques for demultiplexing and add-drop functions and their applications in telecommunication systems based on combinations of OTDM and WDM.
Palle Jeppesen (M'69) was born in Vordingborg, Denmark on August 6, 1941 He received the M.Sc., Ph.D., and Dr.Sc. degrees in electrical engineering from Technical University of Denmark, Lyngby, in 1967, 1970, and 1978, respectively.

From 1968 to 1969, he was a Research Associate at Cornell University, Ithaca, NY, and from 1969 to 1970, a Project Engineer at Cayuga Associates, Ithaca, $\mathrm{NY}$; at both places he did research in the field of GaAs Gunn effect microwave oscillators. From 1970 to 1998, he was an Assistant, Associate, Research and full Professor at EMI, Technical University of Denmark, first in microwave electronics, and since 1974, in optical communications. At EMI, he was Head of Optogroup from 1974 to 1988 and Head of Center for Broadband Telecommunications from 1988 to 1998. From 1982 to 1984, he also worked as part time Manager of R\&D at NKT Elektronik, now Draka Denmark Optical Cable, Lucent Technologies Denmark and Tellabs Denmark. From 1995 to 1998, he coordinated the participation of Technical University of Denmark in the EU ACTS project METON (METropolitan Optical Network). Since 1999, he has been Professor in optical communications at Research Center COM where he is heading the Systems Competence Area. His current research interests are high-speed WDM optical communication systems, in particular, dispersion maps and WDM devices. 